\title{
Controlled Synthesis of $\beta$-SiC Nanopowders with Variable Stoichiometry Using Inductively Coupled Plasma
}

\author{
Y. Leconte $\cdot$ M. Leparoux $\cdot$ X. Portier $\cdot$ N. Herlin-Boime
}

Received: 10 May 2007/Accepted: 11 May 2007/Published online: 7 March 2008

(C) Springer Science+Business Media, LLC 2008

\begin{abstract}
In the growing field of nanomaterials, SiC nanoparticles arouse interest for numerous applications. The inductively coupled plasma (ICP) technique allows obtaining large amount of $\mathrm{SiC}$ nanopowders from cheap coarse $\mathrm{SiC}$ powders. In this paper, the effects on the $\mathrm{SiC}$ structure of the process pressure, the plasma gas composition, and the precursor nature are addressed. The powders were characterized by X-ray diffraction (XRD), Raman and fourier transform infrared (FT-IR) spectroscopy, scanning electron microscopy (SEM) and high resolution electron microscopy (HREM), chemical analyses, BET and photon correlation spectroscopy (PCS) measurements. Whatever the precursor $(\alpha$ - or $\beta$-SiC), the nanoparticles were crystallised in the cubic $\beta$-SiC phase, with average sizes in the $20-40 \mathrm{~nm}$ range. Few residual grains of precursor were observed, and the decarburization due to the reductive $\mathrm{Ar}-\mathrm{H}_{2}$ plasma lead to the appearance of Si nanograins. The stoichiometry of the final product was found to be controllable by the process pressure and the addition of methane.
\end{abstract}

Keywords Powder processing $\cdot$ Nanoparticles $\cdot$ Silicon carbide

\section{Introduction}

SiC materials are widely used in many different kinds of applications. As a ceramic or composite material, it is employed for its lightness, strength, hardness, wear resistance, thermal and electrical conductivities, and high temperature stability. For instance, it can be

Y. Leconte $(\varangle) \cdot$ N. Herlin-Boime

Laboratoire Francis Perrin(CEA-CNRS URA 2453), Service des Photons, Atomes et Molécules, DSM/DRECAM, CEA-Saclay, 91191 Gif sur Yvette Cedex, France

e-mail: yann.leconte@cea.fr

Y. Leconte - M. Leparoux

Laboratory for Materials Technology, Empa-Materials Science and Technology, Feuerwerkerstrasse

39, 3602 Thun, Switzerland

X. Portier

SIFCOM-ENSICAEN, 6 boulevard du maréchal Juin, 14050 Caen cedex, France 
found in rocket engines, turbine blades, structure material for nuclear reactors. When the size of the grains that constitute the ceramic material is decreased to a nanometric scale, the mechanical behaviour is modified and some enhanced or new properties may appear. The use of ultrafine or nanometric powders is an efficient way to overcome the typical drawbacks of carbide ceramics (low ductility, high brittleness). The decrease of the grain size has already been proved to enhance the hardness [1] and to improve the resistance to plasma erosion [2] and to thermal shocks [3]. Moreover, the reinforcement of a composite by a nanometric component can lead to an increase in the performance of the obtained material, as can be seen in the case of $\mathrm{SiC} / \mathrm{TiC}$ composites $[4,5]$. Concerning nuclear applications, the high density of grain boundaries that can be encountered in nanostructured ceramics is assumed to permit a fast recovery of irradiation induced defects [6]. Beside these structure applications, nanosized SiC can also be encountered in other fields such as power components for microelectronic, doping of oxide matrix for luminescence applications [7], or new support for catalysts [8].

New techniques were developed during the last two decades to permit the synthesis of $\mathrm{SiC}$ nanopowders, because the conventional high temperature ways (carboreduction of silica, Acheson process [9]) were unable to produce ultrafine grains. Among these recent techniques, one can find rapid carbothermal reduction [10], sol-gel process [11, 12], CVDbased methods [13, 14], self-propagating high temperature synthesis (SHS [15]), microwave driven reaction [16], or laser pyrolysis [17, 18]. Another approach is to create a plasma to obtain the decomposition of a precursor that can be gaseous, liquid or solid. Different groups around the world have developed such techniques, using different types of precursors $\left(\mathrm{SiO}_{2}+\mathrm{CH}_{4}, \mathrm{Si}\right.$ anode $+\mathrm{CH}_{4}$, coarse $\left.\mathrm{SiC} . ..\right)$ or plasma source (transfer arc, DC or RF thermal plasma...) [19-25]. One of the tricky parts concerning the use of powders as a precursor is to manage to introduce the powder inside the dense plasma. The axial system developed in Empa Thun with the inductively coupled plasma (ICP) torch permits to overcome this problem. The use of this ICP system with SiC coarse powder precursor aiming to synthesize $\mathrm{SiC}$ nanoparticles is reported here.

\section{Experimental Methods}

The ICP setup developed at Empa consists of an induction plasma torch (PL-35, Tekna Plasma systems Inc., Canada) mounted on the top of a $1,500 \mathrm{~mm}$ stainless steel water cooled chamber with an inner diameter of $320 \mathrm{~mm}$. The four turns plasma torch is connected to a radio frequency (RF) generator (Elgotec AG, Switzerland) delivering a maximum of $35 \mathrm{~kW}$ at $13.56 \mathrm{MHz}$. The synthesis reactor is associated with a powder filter unit, a gas-flow control and vacuum system and is schematically presented in Fig. 1.

Coarse microscale SiC inlet powders, $6 \mathrm{H} \alpha$-SiC (SIKA-F1200B, Saint-Gobain Ceramic Materials, Norway) and 3C $\beta$-SiC (B10, H.C.Starck, Germany) with an average particle size around 3 and $1 \mu \mathrm{m}$, respectively were transported with a dense phase convey powderfeeder (Impakt, DACS, Switzerland) and injected axially into the reactor through a $\emptyset 3.75 \mathrm{~mm}$ i.d. water cooled injection probe positioned at $65 \mathrm{~mm}$ above the torch exhaust. In this process, the precursor particles are then heated and evaporated along the high energy plasma and, through a controlled quenching, nanoparticles are produced. These nanopowders were collected into the on-line sampling filter.

Pure argon was used for the central gas and for the carrier gas, whereas some methane can be added to the carrier gas in some cases. The central gas is injected tangentially with a swirl along the injection probe whereas the sheath gas, a mixing of pure $\mathrm{Ar}$ and $\mathrm{H}_{2}$, is 


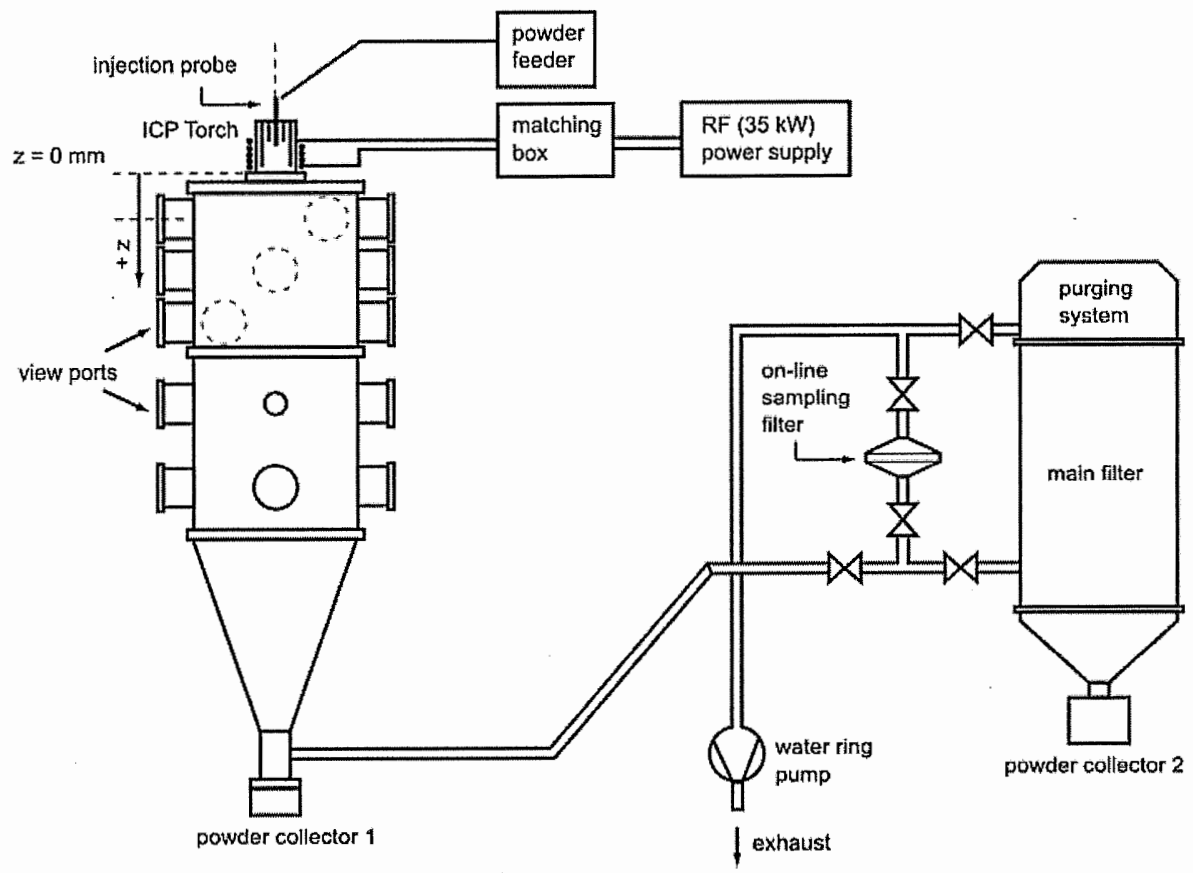

Fig. 1 ICP reactor scheme

introduced axially along the ceramic tube of the torch. In this study, the central gas flow rate was kept constant to $12 \mathrm{slpm}$, while the sheath gas mixture flow rate was fixed to $80 \mathrm{slpm} \mathrm{Ar}+6 \mathrm{slpm} \mathrm{H}_{2}$. Argon was injected for quenching through an eight-nozzle quenching ring located at $z=120 \mathrm{~mm}$ from the torch exhaust ( $z$ reference shown in Fig. 1). According to modelling and enthalpy probe measurements [26, 27], this position corresponds, for the process parameters used for $\mathrm{SiC} 1$ reference sample (see Table 1) to an axial plasma temperature of $3,000^{\circ} \mathrm{C}$. In this paper, only the experiments performed with a constant quenching gas flow rate of $30 \mathrm{slpm}$ are described. The plate power was tuned to $16.25 \mathrm{~kW}$ for each experiment. The variable parameters of this study (precursor crystalline phase, pressure, carrier gas composition) are summarized in Table 1 together with the recorded values of the precursor feed rate.

Table 1 Synthesis parameters for the different samples

\begin{tabular}{lllll}
\hline Sample & $\begin{array}{l}\text { Precursor } \\
\text { phase }\end{array}$ & $\begin{array}{l}\text { Pressure } \\
(\mathrm{kPa})\end{array}$ & $\begin{array}{l}\text { Carrier gas } \\
\text { flow (slpm) }\end{array}$ & $\begin{array}{l}\text { Precursor } \\
\text { feed } \\
\text { rate } \\
\left(\mathrm{g} \mathrm{min}^{-1}\right)\end{array}$ \\
\hline $\mathrm{SiC} 1$ & $6 \mathrm{H}-\mathrm{SiC}$ & 40 & $5 \mathrm{Ar}$ & $2.6 \pm 0.2$ \\
$\mathrm{SiC} 2$ & $6 \mathrm{H}-\mathrm{SiC}$ & 30 & $5 \mathrm{Ar}$ & $3.3 \pm 0.3$ \\
$\mathrm{SiC} 3$ & $6 \mathrm{H}-\mathrm{SiC}$ & 60 & $5 \mathrm{Ar}$ & $2.6 \pm 0.2$ \\
$\mathrm{SiC} 4$ & $6 \mathrm{H}-\mathrm{SiC}$ & 40 & $4.9 \mathrm{Ar}+0.1 \mathrm{CH}_{4}$ & $3.1 \pm 0.3$ \\
$\mathrm{SiC} 5$ & $6 \mathrm{H}-\mathrm{SiC}$ & 40 & $4.7 \mathrm{Ar}+0.3 \mathrm{CH}_{4}$ & $2.6 \pm 0.2$ \\
$\mathrm{SiC} 6$ & $3 \mathrm{C}-\mathrm{SiC}$ & 40 & $5 \mathrm{Ar}$ & $2.7 \pm 0.2$ \\
\hline
\end{tabular}


The obtained powders were characterized by several investigation techniques. Chemical analyses were performed in CNRS laboratory (Vernaison, France) by ICP-OES in order to determine the composition of the $\mathrm{SiC}$ powders, with a relative uncertainty of $3 \%$. X-ray diffraction (XRD) measurements were performed on a Siemens D5000 diffractometer operating with $\mathrm{Cu}-\mathrm{K}_{\alpha 1}$ radiation at $1.540598 \AA$ (diagrams are shown here without the $\mathrm{K}_{\alpha 2}$ contribution). Scanning electron microscopy (SEM) was achieved on a Hitachi HR-SEM S4800 microscope. High resolution electron microscopy (HREM) observations were recorded from a Jeol 2011 FEG microscope operated at $200 \mathrm{kV}$. Raman scattering spectra were acquired on a Renishaw Ramanscope 3000 spectrometer with a $514 \mathrm{~nm}$ probe. The Fourier transform infrared (FT-IR) spectra were recorded on a Perkin-Elmer FT-IR 2000 bench. A Malvern HS1000 apparatus was used to make the photon correlation spectroscopy (PCS) measurements. For this latter investigation, the samples were sonicated in water in order to obtain stable suspensions. The size distributions were recorded both in number of particles (promoting the main population in number, i.e. the small grains in our samples) and in scattered intensity (promoting the most scattering population, i.e. the big particles). The BET specific surface measurements were performed on a Micromeretics Flowsorb 2300 apparatus. The mean grain size $S_{\mathrm{BET}}$ was calculated from the specific surface area $A_{\mathrm{BET}}$ with the following equation:

$$
S_{\mathrm{BET}}=\frac{6}{\rho \cdot A_{\mathrm{BET}}}
$$

where $\rho$ is the powder effective density calculated from chemical analyses results.

\section{Results and Discussion}

A reference sample of $\mathrm{SiC}$ nanopowders (SiC1) was first synthesized with conventional experimental parameters (see Table 1). The results concerning the structural characteristics of this sample are discussed below.

Diffraction pattern recorded from $\mathrm{SiC} 1$ sample can be seen in Fig. 2 together with reference patterns for $\beta$-SiC (cubic, 3C polytype), $\alpha$-SiC (hexagonal, $6 \mathrm{H}$ polytype), and $\mathrm{Si}$. In the same figure is also given the diffraction diagram of the coarse precursor powder. Considering the intensity ratios of the different peaks for $\mathrm{SiC} 1$, one can notice that the main phase is $3 \mathrm{C} \beta$-SiC, with contribution of $6 \mathrm{H} \alpha-\mathrm{SiC}$. A third contribution can be observed, corresponding to the $\mathrm{Si}$ phase (cubic). This is the consequence of the decarburization process consecutive to the reactions of the precursor $\mathrm{C}$ atoms with the $\mathrm{H}$ radicals of the $\mathrm{Ar}-\mathrm{H}_{2}$ plasma. As a matter of fact, the formation of $\mathrm{C}-\mathrm{H}$ bonded molecules (methane, acetylene, ethylene) has been detected by in situ infrared spectroscopy measurements in $\mathrm{Ar}-\mathrm{H}_{2}$ plasmas where carbide powder is introduced. In the present case, the $\mathrm{C}$ atoms come from the precursor SiC powder. These latter are consumed in the hydrocarbon molecules formation, and are no longer available for the creation of $\mathrm{Si}-\mathrm{C}$ bonds. Guo et al. found through thermodynamic calculation in a $\mathrm{Ar}-\mathrm{N}_{2}-\mathrm{CH}_{4}$ plasma with $\mathrm{Si}$ powder as precursor that the formation of pure $\mathrm{Si}$ and free $\mathrm{C}$ phases was possible, together with the formation of $\mathrm{SiC}$. The appearance of these monoatomic phases were found to depend on the $\mathrm{Si} / \mathrm{CH}_{4}$ ratio and on the temperature that can influence the decomposition of $\mathrm{CH}_{4}$ [23]. Even without $\mathrm{H}$ coming from the plasma gas, temperatures above $2,100^{\circ} \mathrm{C}$ lead to the formation of gaseous hydrocarbon species from the decomposition of methane. In the present case, with temperatures as high as $3,000^{\circ} \mathrm{C}$, the $\mathrm{C}$ consuming formation of such gaseous species is probably enhanced. 
Fig. 2 XRD diagrams recorded for the SiC1 sample and for the $\alpha$-SiC precursor powder, together with references patterns for $6 \mathrm{H} \alpha$ $\mathrm{SiC}, 3 \mathrm{C} \beta$-SiC, and $\mathrm{Si}$ phases

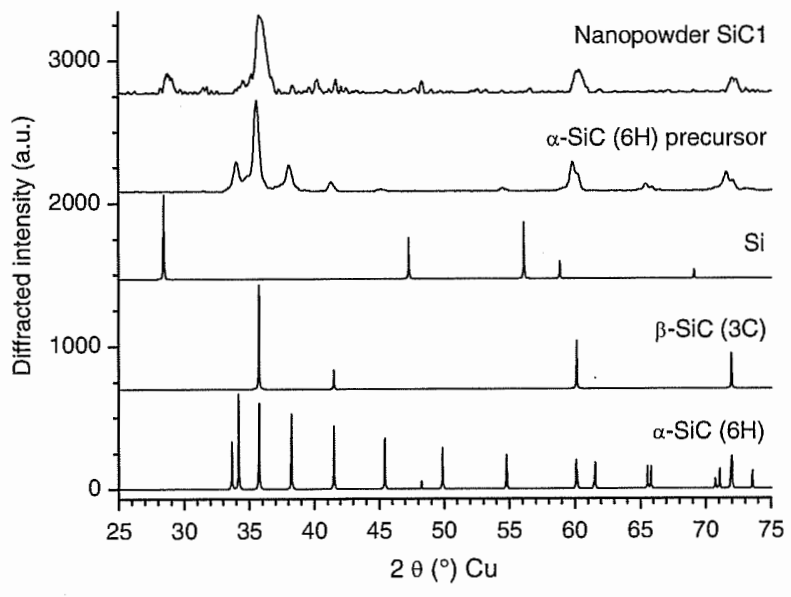

The $\mathrm{SiC} 1$ sample is thus constituted by a mixture of $3 \mathrm{C} \beta-\mathrm{SiC}, 6 \mathrm{H} \alpha-\mathrm{SiC}$, and $\mathrm{Si}$ phases. The presence of the $\alpha$-SiC phase could be attributed to unreacted precursor grains that would not have penetrated the dense plasma and therefore have followed a trajectory at the edge of the plasma tail where the temperature is below the decomposition point of silicon carbide $\left(2,700^{\circ} \mathrm{C}\right)$. From the diffraction patterns, it is however not possible to say whether the $\mathrm{Si}$ and $\beta$-SiC phases can be found as a composite inside a same grain (core-shell or polycrystal-like structure) or in separated grains. The mixture of the three phases, added to the broadening of the diffraction peaks and the poor diffraction signal/noise ratio from the nanograins, makes the phase quantification and the crystallize size measurements from these diagrams very difficult and thus weakly reliable. Nevertheless, considering only the $\beta$-SiC phase, a mean crystallite size can be estimated to $36 \mathrm{~nm}$ from Scherrer's formula applied to the (111), (220), and (311) diffraction peaks FWHM. The peak broadening is assumed to be consecutive to the size decrease as no strain is expected in grains formed in the vapour phase in plasma. The same calculation, when applied to the (111) diffraction line of $\mathrm{Si}$, gives a mean crystallite size in the same order of magnitude $(39 \mathrm{~nm})$. In both cases, one has to take into account the high uncertainty due to the quality of the diagrams. These crystallite sizes, together with their reliability, are in agreement with the grain sizes calculated from BET measurements (see Table 2) close to $30 \mathrm{~nm}$. This latter remark, together with the closeness of the values of the crystallite sizes estimated for $\mathrm{SiC}$ and $\mathrm{Si}$, seem to support the hypothesis describing a mixture of $\mathrm{SiC}$ and $\mathrm{Si}$ separated nanograins instead of a core-shell structure.

Figure 3 shows a Raman spectrum recorded from SiC1 sample. On this spectrum, several contributions can be observed. The two most intense, near 790 and $970 \mathrm{~cm}^{-1}$ can be attributed either to $\beta$-SiC (planar optic mode TO at $796 \mathrm{~cm}^{-1}$, axial optic mode LO at $972 \mathrm{~cm}^{-1}$ ) or to $\alpha$-SiC (TO at $796-797 \mathrm{~cm}^{-1}$, LO at $964-965 \mathrm{~cm}^{-1}$ ) [28]. The weak contribution located near $765 \mathrm{~cm}^{-1}$ is characteristic of the TO mode at $767 \mathrm{~cm}^{-1}$ of the $\alpha$ SiC phase. The broad bands near 1,520,1,620, and $1,710 \mathrm{~cm}^{-1}$ can also be ascribed to optic modes of $\alpha-\mathrm{SiC}$ [29]. The peak near $520 \mathrm{~cm}^{-1}$ is attributed to crystalline Si $\left(521 \mathrm{~cm}^{-1}\right)$. This third phase was already observed on XRD diagrams, and is also detected on the Raman spectrum. Raman spectroscopy is very sensitive to the presence of homoatomic species, as $\mathrm{Si}$ or $\mathrm{C}$, when compared to hetero-atomic species as $\mathrm{SiC}$. Even a small amount of $\mathrm{Si}$ or $\mathrm{C}$ diluted in a $\mathrm{SiC}$ matrix can give a strong scattered intensity. Since no 
Table 2 Characteristics of the different samples: oxygen content, $\mathrm{Si} / \mathrm{C}$ ratio, $\mathrm{R}_{\mathrm{SiC} / \mathrm{Si}}$ and $\mathrm{R}_{\beta / \alpha}$ parameters, BET specific surface area and subsequent size estimation

\begin{tabular}{lcccccc}
\hline Sample & $\mathrm{O}$ (wt\%) & \multicolumn{1}{l}{$\mathrm{Si} / \mathrm{C}$ (at.) } & \multicolumn{1}{c}{$\mathrm{RSiC} / \mathrm{Si}$} & \multicolumn{1}{c}{$\mathrm{R}_{\beta / \alpha}$} & $\mathrm{A}_{\mathrm{BET}}\left(\mathrm{m}^{2} \mathrm{~g}^{-1}\right)$ & $\mathrm{S}_{\mathrm{BET}}(\mathrm{nm})$ \\
\hline $\mathrm{SiC} 1$ & $4.95 \pm 0.15$ & $1.27 \pm 0.08$ & $4.2 \pm 0.3$ & $10.2 \pm 07$ & $65 \pm 1.3$ & $30.7 \pm 1.5$ \\
$\mathrm{SiC} 2$ & $5.17 \pm 0.16$ & $1.23 \pm 0.07$ & $8.3 \pm 0.6$ & $5.0 \pm 0.4$ & $64 \pm 1.3$ & $30.8 \pm 1.5$ \\
$\mathrm{SiC} 3$ & $6.39 \pm 0.19$ & $1.52 \pm 0.09$ & $1.7 \pm 0.1$ & $14.3 \pm 1.0$ & $58 \pm 1.2$ & $35.7 \pm 1.8$ \\
$\mathrm{SiC} 4$ & - & $1.16 \pm 0.07$ & $7.9 \pm 0.6$ & $8.6 \pm 0.6$ & $70 \pm 1.4$ & $27.8 \pm 1.4$ \\
$\mathrm{SiC} 5$ & $3.16 \pm 0.09$ & $0.92 \pm 0.06$ & $\infty$ & $9.9 \pm 0.7$ & $107 \pm 2.1$ & $17.5 \pm 0.9$ \\
$\mathrm{SiC} 6$ & $8.97 \pm 0.27$ & $1.75 \pm 0.10$ & $1.5 \pm 0.1$ & $>20$ & $104 \pm 2.1$ & $20.5 \pm 1.0$ \\
\hline
\end{tabular}

Fig. 3 Raman spectrum recorded for the $\mathrm{SiCl}$ sample with the corresponding peaks attribution

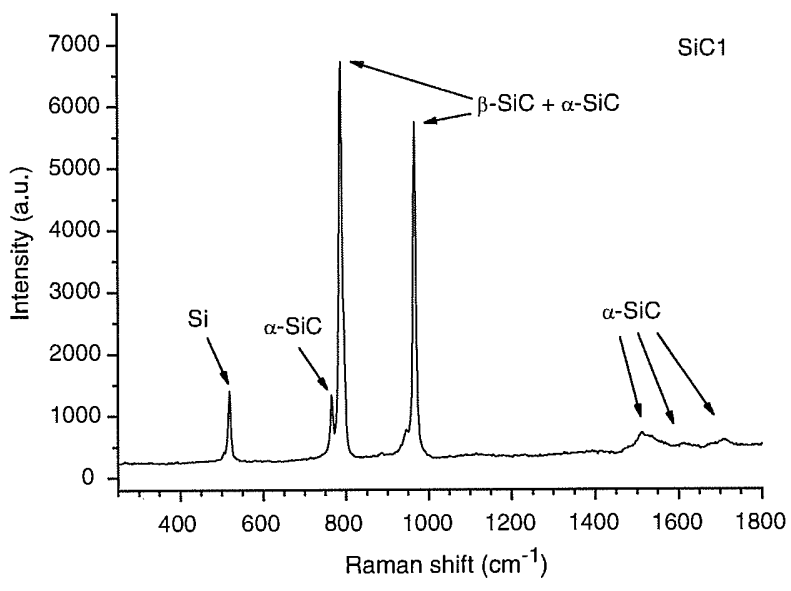

contribution can be observed in the $1,300-1,400 \mathrm{~cm}^{-1}$ region, we can conclude on the absence of amorphous or ordered free $\mathrm{C}$ phase in the powder. This Raman spectrum confirms the observations made from XRD measurements, but does not give an idea of the phase distribution in the powder.

The chemical composition of the SiC1 sample (see Table 2) shows a large excess of Si when compared to stoichiometric $\mathrm{SiC}$. It confirms the decarburiztion of the stoichiometric $\mathrm{SiC}$ precursor within the $\mathrm{Ar}-\mathrm{H}_{2}$ plasma. This large $\mathrm{Si}$ excess is in good agreement with the XRD and Raman observations of a separate silicon phase. Si-SiC nanopowders could be interesting in order to achieve tight $\mathrm{SiC}$ parts where the open porosity would be filled by the $\mathrm{Si}$ excess, as can be seen in reaction-bounded $\mathrm{Si}$ infiltrated $\mathrm{SiC}$. Nevertheless, the counterpart of this Si excess could be a high content of oxygen, as this latter element is very sensitive to room temperature oxidization. However, the oxygen pollution is lower than $5 \mathrm{wt} \%$, which is not a high content if one takes into account the fast oxidization rate of nanopowders when compared to micrometric sized grains. These oxygen atoms come on the one hand from the oxidization of the Si excess in air after synthesis, and on the second hand from the air that is introduced inside the chamber during the process from the precursor powder tank. This air pollution also generates the small content in N. This is confirmed by the oxygen contents of the $\mathrm{SiC} 2$ to SiC6 samples (that will be addressed later in this paper), that increase with the $\mathrm{Si} / \mathrm{C}$ ratio. 
SEM picture recorded from SiC1 sample is presented in Fig. 4a. The grains size distribution and shapes appear to be inhomogeneous. A first population of nanograins can be observed, with grain sizes in the same order of magnitude as the crystallite size estimated from XRD diagrams for $\mathrm{SiC}$ or Si phase, meaning about $30 \mathrm{~nm}$. This average size is in rather good agreement with the BET measured sizes (see Table 2). Concerning this first population, the size distribution ranges from $10 \mathrm{~nm}$ to $50 \mathrm{~nm}$, which is rather narrow for plasma synthesized powders if one takes into account the distribution of the temperatures and velocities inside the plasma. The shapes of the grains are different from one to another, far from being spherical. Another population can be observed (see insert of Fig. 4a), constituting a minority. These grains, which sizes range from the submicron scale to a few microns, are very few when compared to the amount of the first population (nanograins) and show a shape with sharp edges similar to the one of raw precursor powder grains (see Fig. 4b). These big grains are strongly assumed to be some residuals of the starting $\alpha$-SiC precursor powder. If this assumption turns to be true, it would support the hypothesis that attributes the $\alpha$-SiC phase seen on XRD diagrams and on Raman spectrum to non-fully evaporated precursor grains.

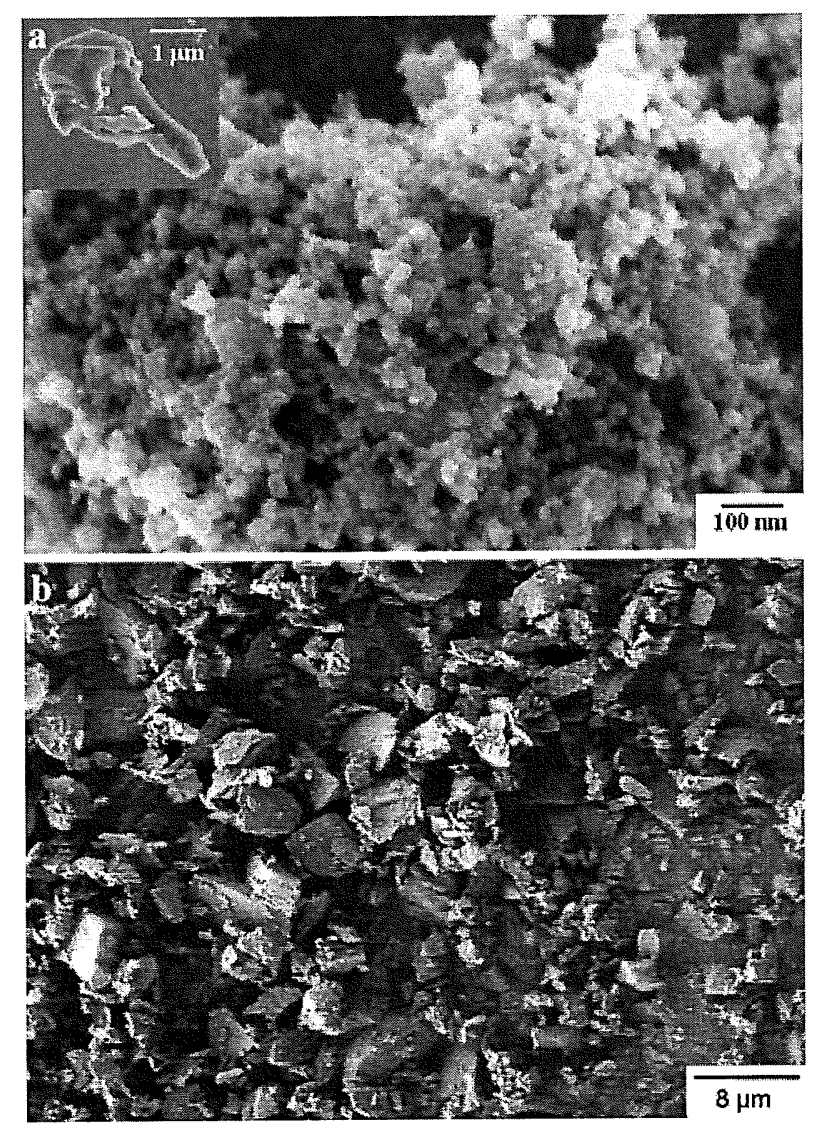

Fig. 4 (a) SEM picture recorded for the SiC1 sample, with a picture of a precursor residual grain in the insert. (b) SEM picture recorded for the raw $\alpha$-SiC precursor powder 


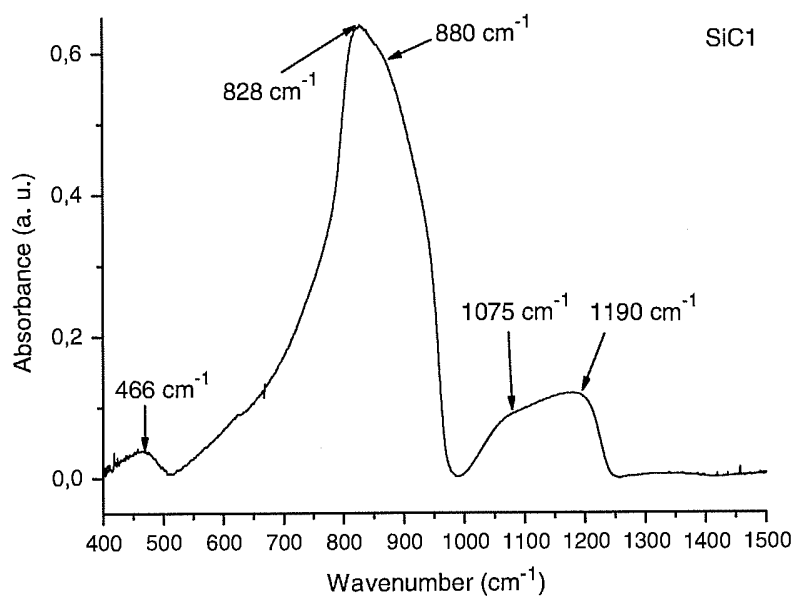

Fig. 5 IR spectrum acquired for the SiC1 sample with the corresponding bands positions

Figure 5 shows an infrared spectroscopy absorption spectrum from SiC1 sample. Bulk or polycrystalline films of $\mathrm{SiC}$ are known to exhibit an absorption band near $793 \mathrm{~cm}^{-1}$, but when small-grained powders are concerned the absorption spectrum is redshifted with a shift depending on the grains shape [30]. The crystalline phase does not seem to play a key role on the absorption bands wavelengths, excepted when one polytype generates a particular shape for the nanoparticles. If the grains are purely spherical, the absorption band is shifted to $900-930 \mathrm{~cm}^{-1}$, while the peak appears near $820-860 \mathrm{~cm}^{-1}$ for oblate and/or prolate spheroids. In Fig. 5, the main peak is found near $830 \mathrm{~cm}^{-1}$, with a shouldered component near $880 \mathrm{~cm}^{-1}$. It means that the nanograins are not spherical (confirmed by SEM observations in Fig. 4), but exhibit different shapes in a continuous distribution that leads to a single IR absorption band resulting from several contributions. The three other bands that can be observed near $466 \mathrm{~cm}^{-1}, 1,075 \mathrm{~cm}^{-1}$, and $1,190 \mathrm{~cm}^{-1}$ are characteristics of $\mathrm{Si}-\mathrm{O}$ bonds.

The size distribution was investigated using PCS measurements performed on the SiC1 sample. The results are given in Fig. 6. The presence of small isolated nanograins is observed, together with very few big entities (100-300 nm) only seen in intensity measurements because of their small amount. This latter contribution can come from agglomerates that were not broken by the sonication treatment, or from the precursor residuals incompletely evaporated. The average grain size was found to be about $20 \mathrm{~nm}$ for this batch where no big entities with size in the micron range could be observed. Nevertheless, such big particles could be observed in other batches of the same sample, corresponding to the ones observed in the insert of Fig. 4a. The corresponding diagrams are not shown here, because the detector was blinded by the signal coming from the big particles and was thus unable to detect the contribution of the small isolated particles.

The XRD measurements, as well as the Raman spectra, do not allow us to distinguish whether one actually deals with a mixture of separate grains of different phases, or several phases inside a same grain (core/shell structure). In order to determine the distribution of the phases in the sample SiC1, HREM observations were performed on this sample and are shown in Fig. 7a-e. Figure 7a gives an overview of the size and shape distribution in the powder. The insert of Fig. 7a shows a diffraction pattern where several diffraction rings 
Fig. 6 PCS size distribution in number and intensity recorded for the SiC1 sample
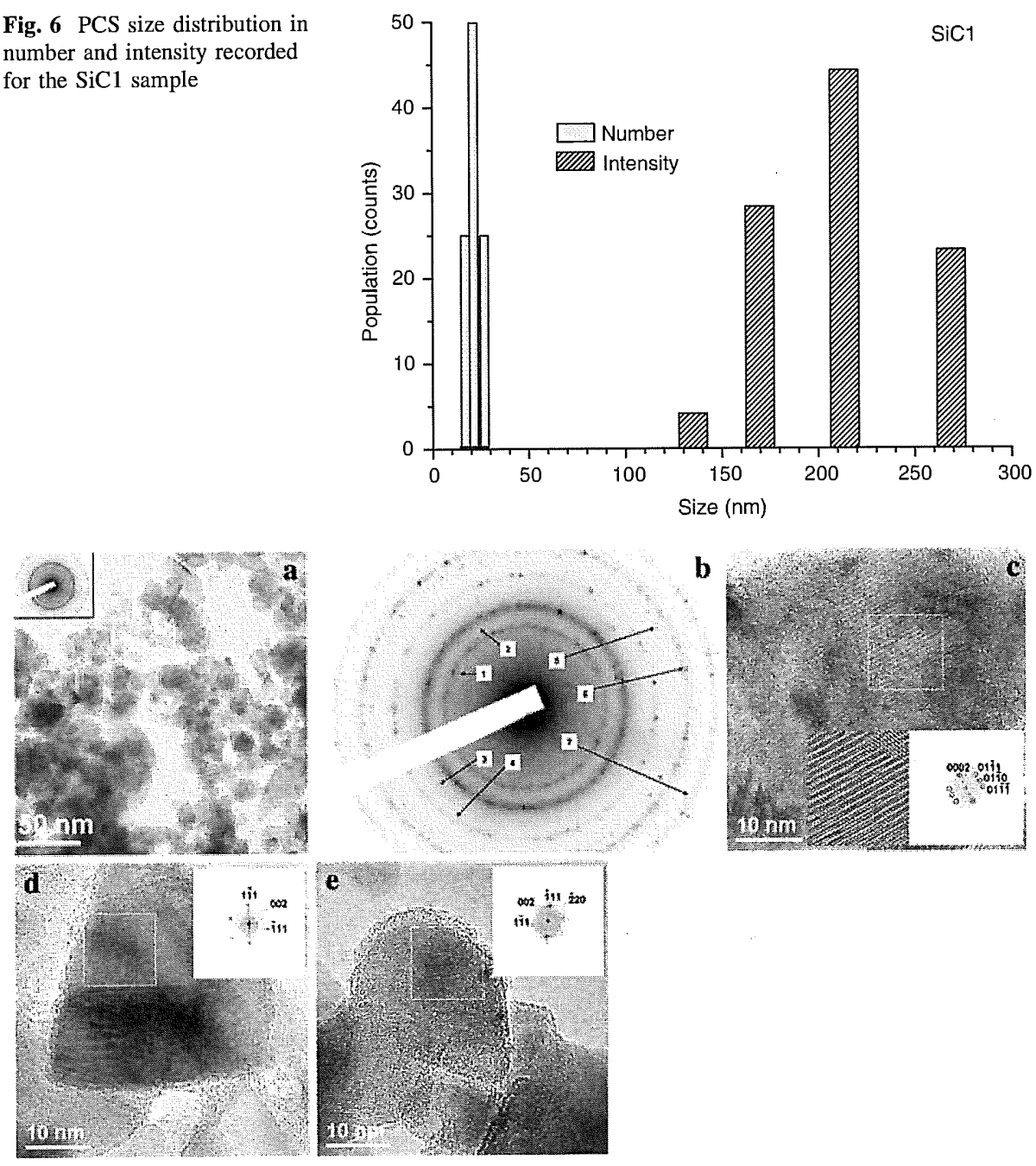

Fig. 7 (a) TEM picture of the SiC1 sample, with the corresponding diffraction pattern in the insert. (b) TEM diffraction pattern recorded for the $\mathrm{SiC} 1$ sample, with labelled diffraction rings (see Table 3). (c) HREM picture of a $\alpha-\mathrm{SiC}$ nanograin for the $\mathrm{SiC} 1$ sample. In the insert, a magnification of the white framed area together with the corresponding indexed Fourier transform. (d) HREM picture of a $\beta$-SiC nanograin for the $\mathrm{SiC} 1$ sample. In the insert, a magnification of the white framed area together with the corresponding indexed Fourier transform. (e) HREM picture of a Si nanograin for the $\mathrm{SiCl}$ sample. In the insert, a magnification of the white framed area together with the corresponding indexed Fourier transform

can be seen, corresponding to different phases in random orientation (powder diagram). Considering each diffraction ring, the $d_{h k l}$ spacing can be calculated and the different phases can be identified. From the pattern seen in Fig. 7b, the $\beta$-SiC, $\alpha$-SiC, and Si phases can be recognized (see the indexation of the diffraction rings in Table 3 ), confirming the XRD observations. A careful exploration of the different grains seen in Fig. 7a was performed in order to identify the repartition of the different phases. Figure $7 \mathrm{c}$ shows a typical picture of a $\alpha$-SiC grain, oriented along the [2-1-10] direction. The hexagonal structure 
Table 3 Attribution of the different numbered diffraction rings of Fig. $7 \mathrm{~b}$ to the main phase contributions

\begin{tabular}{llrl}
\hline $\begin{array}{l}\text { Diffraction } \\
\text { ring }{ }^{\circ}\end{array}$ & $\mathrm{d}(\AA)$ & Planes & \multicolumn{1}{c}{$\begin{array}{l}\text { Crystalline } \\
\text { phase }\end{array}$} \\
\hline 1 & $3.14 \pm 0.05$ & $(111)$ & $\mathrm{Si}$ \\
2 & $2.62 \pm 0.05$ & $(10-11)$ & $\alpha$-SiC \\
& $2.51 \pm 0.05$ & $(111)$ & $\beta$-SiC \\
& $2.50 \pm 0.05$ & $(10-12)$ & $\alpha$-SiC \\
3 & $2.17 \pm 0.05$ & $(200)$ & $\beta$-SiC \\
4 & $1.90 \pm 0.05$ & $(220)$ & $\mathrm{Si}$ \\
5 & $1.64 \pm 0.05$ & $(311)$ & $\mathrm{Si}$ \\
6 & $1.54 \pm 0.05$ & $(220)$ & $\beta-\mathrm{SiC}$ \\
& $1.54 \pm 0.05$ & $(11-20)$ & $\alpha-\mathrm{SiC}$ \\
7 & $1.36 \pm 0.05$ & $(400)$ & $\mathrm{Si}$ \\
& $1.31 \pm 0.05$ & $(311)$ & $\beta-\mathrm{SiC}$ \\
& $1.31 \pm 0.05$ & $(11-26)$ & $\alpha$-SiC \\
\hline
\end{tabular}

can be clearly seen in the magnified area corresponding to the white frame. By means of a Fourier transform of this area, the diffraction pattern can be re-built. This pattern is also given in the insert, and shows the diffraction spots corresponding to the (0002), (01-11), $(01-10)$, and $(01-1-1)$ planes of a monocrystalline hexagonal phase of SiC. All the hexagonal grains that were observed were a few hundred $\mathrm{nm}$ in size. Concerning the cubic phases, SiC and Si separate grains were found. Figure $7 \mathrm{~d}$ exhibits a grain of $\beta$-SiC oriented in the [110] direction. The same treatment as for Fig. $7 \mathrm{c}$ was applied to the white frame area of Fig. 7d, and the corresponding diffraction pattern is shown in the insert. The diffraction spots correspond to the $(1-11),(002)$, and $(-111)$ planes of a monocrystalline cubic phase of SiC. Most of the cubic SiC grains were in the $10-50 \mathrm{~nm}$ range. Figure $7 \mathrm{e}$ shows a picture of a Si grain (cubic) oriented in the [110] direction. The diffraction pattern, shown in the insert and calculated from a Fourier transform of the area in the white frame, reports the diffraction spots corresponding to the $(1-11),(002),(-111)$, and $(-220)$ planes of a monocrystalline cubic phase of Si. Most of the Si grains were also in the $10-50 \mathrm{~nm}$ range.

These HREM observations confirm the previous characterization results concerning the sizes and the crystalline phases, and clarify the distribution of these phases in the powder. The $\alpha-\mathrm{SiC}$ phase is due to the presence of some residuals of the starting $\alpha-\operatorname{SiC}$ powder which grains were not all fully vaporized in the plasma. The real products of the process are thus only cubic, and consist in a mixture of $\mathrm{SiC}$ and $\mathrm{Si}$ separate grains in the 10-50 $\mathrm{nm}$ range.

In order to obtain a pure $\beta$-SiC nanopowder, the two other phases should be eliminated. To avoid the presence of $\alpha$-SiC precursor residuals, the process parameters (pressure in particular) can be modified to enhance the vaporization of the coarse grains. Another way, as we will see further in this work, is to use a $\beta$-SiC precursor. The use of a smaller-grained precursor should also permit to decrease the amount of residuals, as small grains will be easier to vaporize completely. This latter possibility is out of the scope of this paper, and will be addressed in future work.

The process pressure was tuned in order to optimize the evaporation of the starting $\alpha-\mathrm{SiC}$ precursor. Even if the pressure does not influence much the temperature of the plasma down to the quenching ring, it has a strong influence on the gas velocity and 

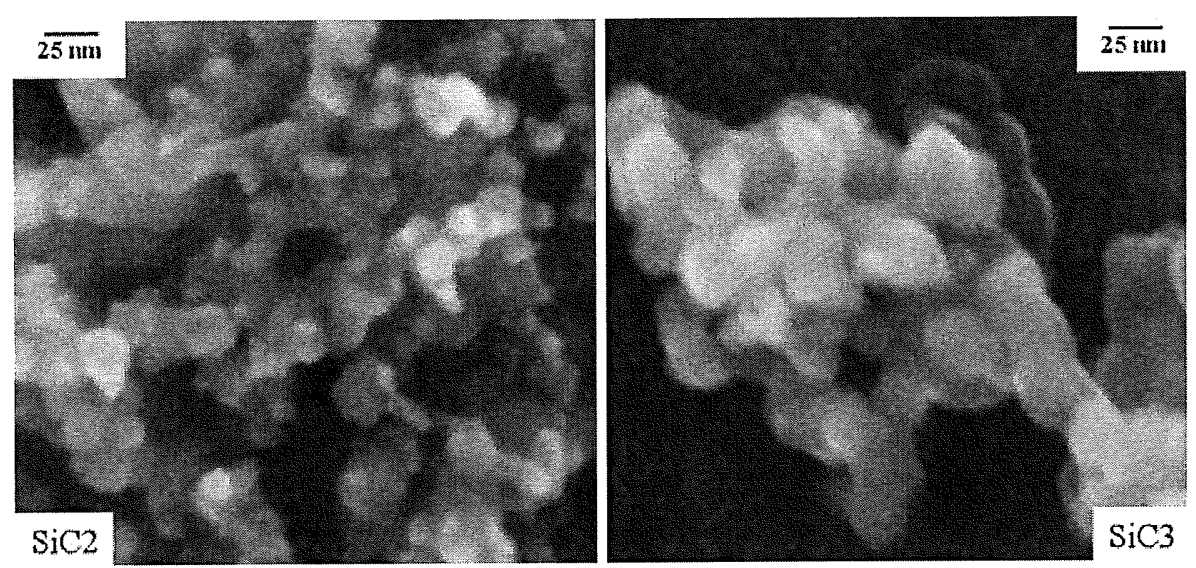

Fig. 8 SEM pictures recorded for the $\mathrm{SiC} 2$ and $\mathrm{SiC} 3$ samples

consequently on the residence time of the particles within the hot zone. Assuming the particles have the same velocity as the plasma gases, the dwell times at $T \geq 3,000^{\circ} \mathrm{C}$ till the quenching ring calculated from modelling with a $10 \mathrm{~kW}$ net plasma power are 1.11 , 1.49 and $3.24 \mathrm{~ms}$ for process pressures of 30,40 and $60 \mathrm{kPa}$, respectively. Therefore at high pressure, more precursor material should be evaporated and then less $\alpha$-SiC should be present in the final product.

Concerning the process pressure, two samples were prepared for $P=30 \mathrm{kPa}$ (SiC2) and $P=60 \mathrm{kPa}(\mathrm{SiC} 3)$ with the same position of the quench ring, in order to be compared to $\mathrm{SiC} 1(P=40 \mathrm{kPa})$. Figure 8 shows two SEM pictures recorded at the same magnification for SiC2 and SiC3 samples. The powder synthesized for the low value of pressure exhibits smaller grains than the one at high pressure. This is confirmed by the BET measurements (see Table 2). At low pressure, the growth of the particles is limited because the collision between the growing grains that can lead to coalescence is inhibited. Moreover, the longer residence time observed at $P=60 \mathrm{kPa}$ enhances the growth of the particles.

At high pressure, the species remain longer in a hot zone where hydrogen molecules are at least partially decomposed (the decomposition of $\mathrm{H}_{2}$ starts at about $2,000 \mathrm{~K}$ and reaches a maximum at about $4,000 \mathrm{~K}$ [31]). This reducing atmosphere promotes the decarburization process as seen from the chemical compositions of the powders given in Table 2 . This is also confirmed by the XRD diagrams shown in Fig. 9 and recorded for SiC2 and $\mathrm{SiC} 3$ samples.

As mentioned before, the quality of the diffraction data did not permit the reliable refinement of the diagrams according to the Rietveld method, in order to quantify the phase ratio. Nevertheless, a qualitative observation of the evolution of the intensity ratios with the process pressure for some particular peaks can give a good idea of the effect of the pressure on the presence of the different phases. Concerning the cubic and hexagonal phases of SiC, the intensity of the peak located near $36^{\circ}$ results mainly from the intensity of the (111) line of $\beta$-SiC (main phase), but also from the (006) and (102) lines of $6 \mathrm{H} \alpha-\mathrm{SiC}$ as a smaller contribution. The peak located near $38^{\circ}$ is exclusively attributed to the (103) of $6 \mathrm{H} \alpha-\mathrm{SiC}$. The evolution of the intensity ratio between these two peaks should thus be qualitatively representative of the evolution of the phase ratio between the cubic and hexagonal phases of $\mathrm{SiC}$. In this context, the $\mathrm{R}_{\beta / \alpha}$ ratio was calculated from the formula given below: 


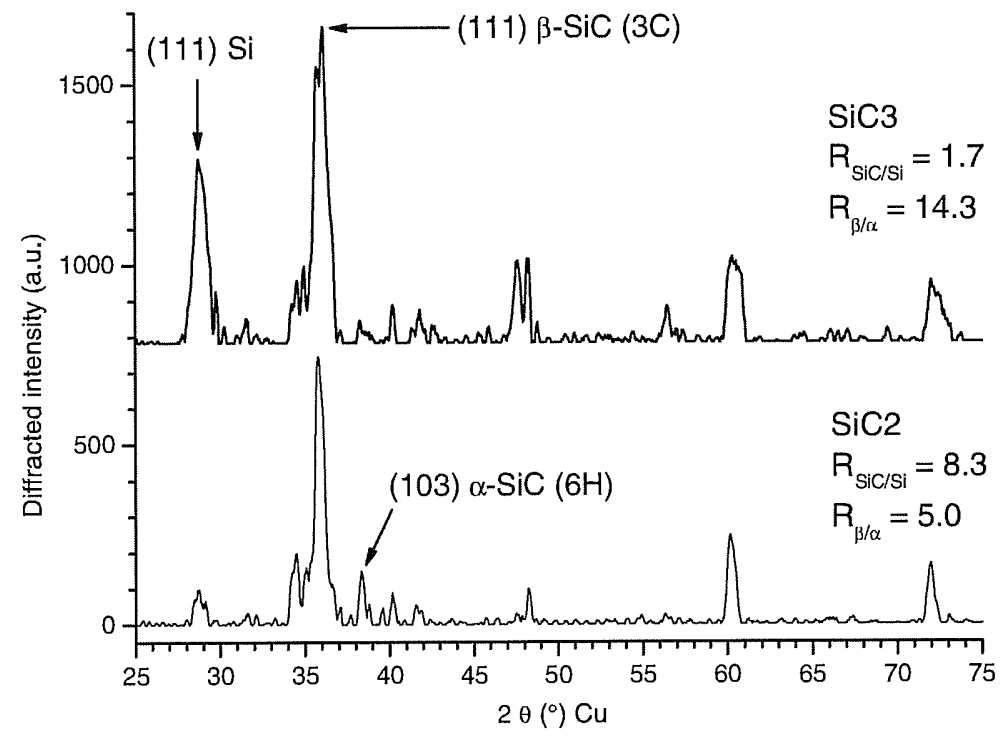

Fig. 9 XRD diagrams recorded for the $\mathrm{SiC} 2$ and $\mathrm{SiC} 3$ samples, with partial peaks indexation. The calculated values for $\mathrm{R}_{\beta / \alpha}$ and $\mathrm{R}_{\mathrm{SiC} / \mathrm{Si}}$ parameters are also given

$$
\mathrm{R}_{\beta / \alpha}=\frac{\mathrm{I}\left(\beta-\operatorname{SiC}_{(111)}\right)}{\mathrm{I}\left(\alpha-\operatorname{SiC}_{(103)}\right)}
$$

where $\mathrm{I}\left(\beta-\mathrm{SiC}_{(111)}\right)$ is the intensity of the diffraction peak near $36^{\circ}$ (mainly (111) of $\beta$-SiC), and $\mathrm{I}\left(\alpha-\mathrm{SiC}_{(103)}\right)$ the intensity of the (103) diffraction peak for $6 \mathrm{H} \alpha-\mathrm{SiC}$ (near $38^{\circ}$ ). The values were found to be $\mathrm{R}_{\beta / \alpha}=5.0$ for $\mathrm{SiC} 2$ and $\mathrm{R}_{\beta / \alpha}=14.3$ for SiC3, which indicates a larger amount of hexagonal phase in $\mathrm{SiC} 2$ sample, synthesized for the low value of the pressure $(P=30 \mathrm{kPa})$. As expected from the residence time consideration, the increase of the process pressure appears to be an efficient way to lower the amount of residual precursor in the final powder.

Considering now the $\mathrm{SiC} / \mathrm{Si}$ ratio, i.e. the decarburization, the same qualitative approach can be followed from the Fig. 9. This time, the intensity of the peak located near $29^{\circ}$ and exclusively attributed to the (111) line of the Si phase will be compared to the intensity of the peak near $36^{\circ}$ already addressed in the previous section. From these two peaks, the $\mathrm{R}_{\mathrm{SiC} / \mathrm{Si}}$ ratio is calculated as follows:

$$
\mathrm{R}_{\mathrm{SiC} / \mathrm{Si}}=\frac{\mathrm{I}\left(\beta-\mathrm{SiC}_{(111)}\right)}{\mathrm{I}\left(\mathrm{Si}_{(111)}\right)}
$$

where I $\left(\mathrm{Si}_{(111)}\right)$ the intensity of the (111) diffraction peak for $\mathrm{Si}$. This ratio is much higher for $\mathrm{SiC} 2\left(\mathrm{R}_{\mathrm{SiC} / \mathrm{Si}}=8.3\right.$ instead of 1.7 for $\left.\mathrm{SiC} 3\right)$, supporting the explanation of the lower efficiency of the decarburization at low pressure. This lower efficiency can be attributed to the smaller amount of hydrogenous species available at low pressure and to the shorter residence time (in comparison with SiC3). Finally, the use of a low pressure was identified as the most likely to limit the decarburization process. 
Fig. 10 XRD diagrams recorded for the SiC4 and SiC5 samples. The calculated value for the $\mathrm{R}_{\mathrm{SiC} /}$ Si parameter is also given

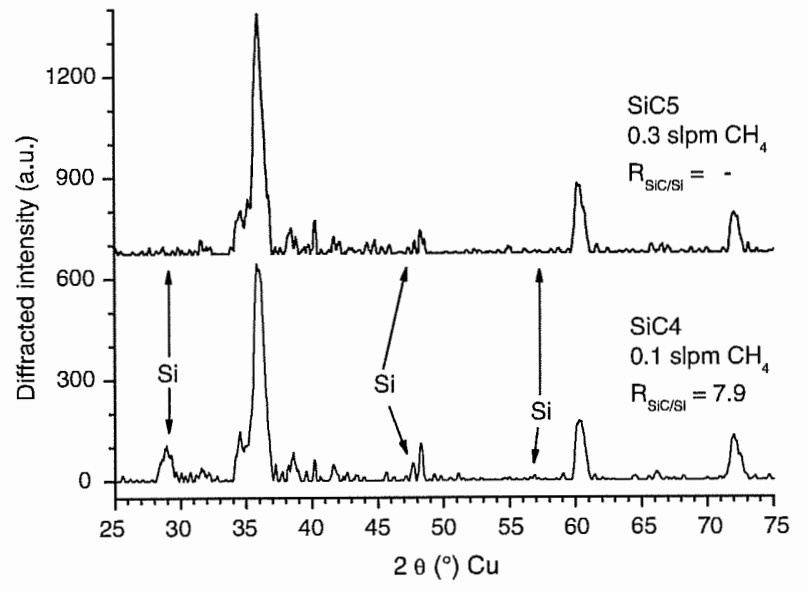

In order to compensate the decarburization that leads to a Si excess in the final nanopowder, SiC4 and SiC5 samples were synthesized with an addition of methane (respectively $0.1 \mathrm{slpm}$ for $\mathrm{SiC} 4$ and $0.3 \mathrm{slpm}$ for SiC5) in the Ar carrier gas. The other parameters were kept equal to the ones used for SiC1 sample (see Table 1). The corresponding diffraction diagrams are shown in Fig. 10. The same hexagonal and cubic phases of $\mathrm{SiC}$ as for $\mathrm{SiC1}$ (synthesized without $\mathrm{CH}_{4}$, see Fig. 2) can still be observed, the remarks concerning this latter sample are also valid for SiC4 and SiC5. The difference with SiC1 consists in the decrease of the Si phase peak intensity. This decrease can already be clearly seen for the SiC4 sample (see Table 2 for $\mathrm{R}_{\mathrm{SiC} / \mathrm{Si}}$ values). For SiC5 sample, the Si phase cannot be seen anymore by XRD. The efficient compensation of the decarburization by the addition of $\mathrm{CH}_{4}$ is also confirmed by the chemical composition of the powders given in Table 2. The BET measurements seem to indicate a very small grain size for the SiC5 sample, which is also the only sample containing an excess of $\mathrm{C}$. This could be the consequence of the formation of carbon black small particles in this sample elaborated with the largest amount of methane. In that case, the BET size value given in Table 2 would not be representative for the $\mathrm{SiC}$ nanograins but result from an average of the carbon black particles with $\mathrm{SiC}$ grains. The presence of free carbon, that is not sensible to air oxidization at room temperature, could also explain the poor content in oxygen of SiC5 sample. On the other hand, free carbon on the surface of the nanograins can lead to a poor densification of the ceramic parts after sintering, because of the perturbation it can induce in the matter diffusion-lead processes between the grains. In such a case, the final mechanical properties of the obtained nanostructured ceramic could be depredated.

SiC6 sample was synthesized with the same process conditions as $\mathrm{SiC} 1$, but this time with a $\beta$-SiC precursor. Figure 11 shows the XRD diagram recorded for the SiC6 sample and for the coarse precursor. As previously discussed for $\mathrm{SiC} 1$ sample, the decarburization generated by the $\mathrm{Ar}-\mathrm{H}_{2}$ plasma can be identified by the appearance of the Si phase lines in the produced nanopowder SiC6. The 3C $\beta$-SiC phase is obviously the dominating phase in SiC6 sample, as the precursor residuals also contribute to the cubic diffraction lines, together with the nanopowder itself. Nevertheless, a weak contribution of a hexagonal phase could be observed. In order to see if it was possible to find $\alpha$-SiC grains in the powder, HREM observations were performed on the SiC6 sample. Each observed nanograin was in the cubic phase, but in some cases some stacking faults are visible inside the 
Fig. 11 XRD diagrams recorded for the SiC6 sample and for the $\beta$-SiC precursor powder
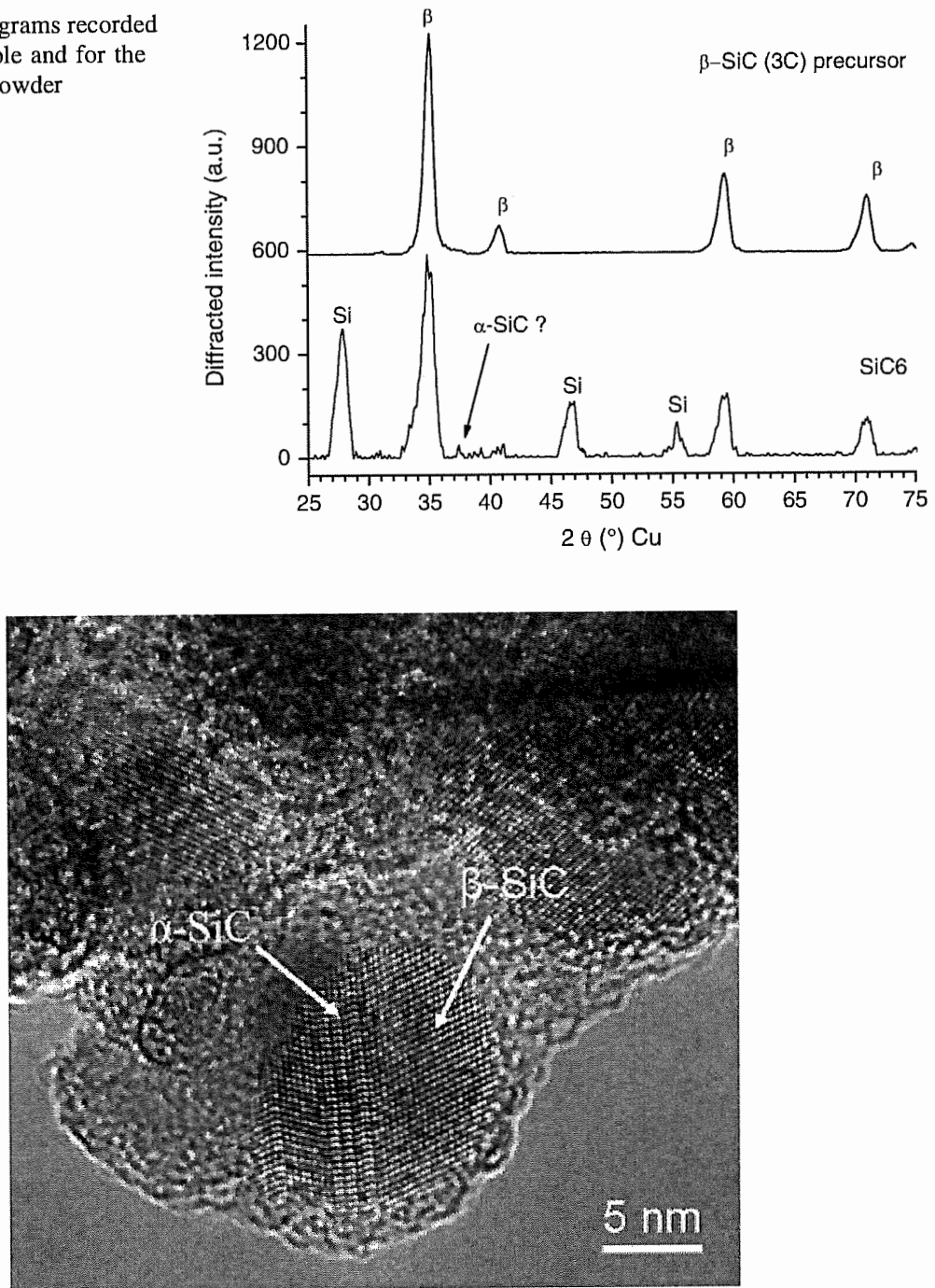

Fig. 12 HREM picture of a nanograin for the SiC6 sample. The grain is mainly cubic, but its middle part is compatible with $\alpha$-SiC structure

cubic grains. The presence of these structural defects can generate some hexagonal regions in the cubic grains, as shown in Fig. 12. Such presence of hexagonal phase ascribed to stacking faults in the cubic phase has already been observed in the case of SiC thin films [32]. This could explain the small $\alpha$-SiC contribution seen in Fig. 11. The HREM observations performed on this sample (as well as SEM pictures not given here) showed that there were much less of these residuals when compared to the samples synthesized from $\alpha$-SiC precursor. This can be ascribed to the smaller size of the cubic precursor coarse grains $(1 \mu \mathrm{m}$ instead of $3 \mu \mathrm{m}$ for the hexagonal ones). The small grains are more efficiently evaporated. The poor content in precursor residuals can also explain the small grain size deduced from BET measurements (see Table 2). The sizes calculated for the other 
samples, that contain more big residuals particles, are certainly overestimated because the specific surface measurement takes into account the contribution of grain sizes in the micron range.

\section{Conclusion}

The plasma synthesis allows the efficient production of SiC nanopowders from coarse SiC powders through an evaporation/condensation process. The mean size of the nanoparticles is around $30 \mathrm{~nm}$. Whatever the crystalline phase of the coarse precursor, $\beta$-SiC cubic phase is obtained in the $\mathrm{SiC}$ nanopowder. Few residual precursors grains are also observed, their presence explains the hexagonal contribution in diffraction diagrams and Raman spectra that was observed for the nanopowders synthesized from $\alpha$-SiC precursor. A Si phase is also present in some samples, as a result of the starting $\mathrm{SiC}$ decarburization by the $\mathrm{Ar}-\mathrm{H}_{2}$ plasma.

The control of the $\beta$-SiC nanopowder stoichiometry, that is very crucial for the mechanical properties of the future nanostructured ceramics, was found to be possible through the tuning of the $\mathrm{Ar}-\mathrm{H}_{2}$ plasma properties. On the one hand, $\mathrm{H}_{2}$ promotes the formation of free $\mathrm{Si}$, leading to the production of $\mathrm{Si}-\mathrm{SiC}$ nanopowders that can be interesting for the filling of open porosities but could also lead to high oxygen content. On the second hand, the addition of $\mathrm{CH}_{4}$ compensates the decarburization process but leads probably to the formation of free carbon that can lower the densification during sintering. A low process pressure was found to decrease the decarburization efficiency, but also to limit the evaporation yield of the precursor, leading to a larger content of hexagonal precursor residuals.

Further investigations are now in progress in order to control the grain size together with the size distribution (effects of the quench gas flow rate and nature, central gas flow rate...). These studies also aim to obtain a pure cubic phase of $\mathrm{SiC}$ without any $\mathrm{Si}$ grains or residuals of the precursor.

Acknowledgements The authors thank C. Schreuders, G. Bürki, and M. Aeberhard (EMPA Thun) for modelling, SEM observations, and XRD characterizations respectively, W. Graehlert (FhG-IWS, Dresden) for Raman spectroscopy, J. Glory and A. Habert (LFP Saclay) for PCS and BET measurements respectively, O. Syrdal (Saint-Gobain) for the SiC microscale powder.

\section{References}

1. Vassen R, Stöver D (1997) Phil Mag B 76:585

2. Vassen R, Kaiser A, Stöver D (1996) J Nucl Mater 233-237:708

3. Donato A, Borsella E, Botti S, Martelli S, Nannetti CA, Mancini MR, Morjan IJ (1996) Nucl Mater 233-237:814

4. Chae KW, Niihara K, Kim DY (1995) J Mat Sci Lett 14:1332

5. Endo H, Ueki M, Kubo HJ (1991) Mat Sci 26:3769

6. Vassen R, Stöver D (2001) Mat Sci Eng A 301:59

7. Fu Z, Ning J, Yang B, Wu W, Pan H, Xu P (2003) Mater Lett 57:1910

8. Ledoux MJ, Pham-Huu C (2001) CaTTech 5:226

9. Guichelaar PJ (1997) In: Carbide, nitride and boride materials synthesis and processing. Chapman and Hall

10. Setiowati U, Kimura SJ (1997) Am Ceram Soc 80:757

11. Hatakeyama F, Kanzaki SJ (1990) Am Ceram Soc 73:2107

12. Seong IS, Kim CH (1993) J Mater Sci 28:3277 
13. Klein S, Winterer M, Hahn H (1998) Chem Vapor Depos 4:143

14. Chen LD, Goto T, Hirai TJ (1989) Mater Sci 24:3824

15. Yamada O, Miyamoto Y, Koizumi MJ (1986) Mater Res 1:275

16. Satapathy LN, Ramesh PD, Agrawal D, Roy R (2005) Mater Res Bull 40:1871

17. Suyama Y, Marra RM, Haggerty JS, Bowen HK (1985) Am Ceram Soc Bull 64:1356

18. Cauchetier M, Croix O, Luce M (1998) Adv Ceram Mat 3:548

19. Ando Y, Ohkohchi M, Uyeda R (1980) Jpn J Appl Phys 19:693

20. Inoue Y, Nariki Y, Tanaka KJ (1989) Mater Sci 24:3819

21. Hollabaugh CM, Hull DE, Newkirk LR, Petrovic JJ (1983) J Mater Sci 18:3190

22. Kameyama T, Sakanaka K, Motoe A, Tsunoda T, Nakanaga T, Wakayama NI, Takeo H, Fukuda K (1990) J Mater Sci 25:1058

23. Guo JY, Gitzhofer F, Boulos MI (1995) J Mater Sci 30:5589

24. Kong P, Pfender E (1987) Langmuir 3:259

25. Lee HJ, Eguchi K, Yoshida T (1990) J Am Ceram Soc 73:3356

26. Leparoux M, Schreuders C, Shin JW, Siegmann S (2005) Adv Eng Mater 7:349

27. Shin JW, Miyazoe H, Leparoux M, Siegmann S, Dorier JL, Hollenstein C (2006) Plasma Sources Sci Technol 15:441

28. Nakashima S, Harima H (1997) Phys Stat Sol A 162:39

29. Burton JC, Sun L, Long FH, Feng ZC, Ferguson T (1999) Phys Rev B 59:7282

30. Papoular R, Cauchetier M, Begin S, Le Caer G (1998) Astron Astrophys 329:1035

31. Boulos MH, Fauchais P, Pfender E (1994) In: Thermal plasmas-fundamentals and applications. Plenum Press editors

32. Colder H, Rizk R, Morales M, Marie P, Vicens J, Vickridge I (2005) J Appl Phys 98:024313 